\title{
RELATOS DOS USUÁRIOS SOBRE AS CONTRIBUIÇÕES DO ACERVO CELPE-BRAS PARA A PROMOÇÃO DA LÍNGUA PORTUGUESA
}

\author{
Ellen Yurika Nagasawa ${ }^{1}$ \\ Luiza Sarmento Divino \\ Juliana Roquele Schoffen ${ }^{3}$
}

\begin{abstract}
Resumo: O Certificado de Proficiência em Língua Portuguesa para Estrangeiros, Celpe-Bras, é o exame brasileiro de proficiência em língua portuguesa, desenvolvido pelo Ministério da Educação do Brasil, aplicado desde 1998. Em 2014, foi disponibilizado publicamente o Acervo Celpe-Bras, uma plataforma online que reúne todos os documentos, provas, manuais e demais dados a respeito do exame, desenvolvido pelo grupo de pesquisa Avalia, da Universidade Federal do Rio Grande do Sul. A disponibilização do Acervo foi de extrema relevância para democratizar o acesso aos dados do Celpe-Bras. Com o intuito de investigar o impacto que a disponibilização pública desses materiais teve para o ensino e aprendizagem de Português como Língua Adicional e para a preparação dos examinandos, bem como de mapear o perfil dos usuários do Acervo, foi elaborado um questionário online, que ficou disponível no portal, com convite para participação voluntária a todos os usuários que acessaram o Acervo no período que compreendeu as inscrições e a aplicação da prova de 2018. Este artigo apresenta dados quantitativos e qualitativos, que indicam o impacto da disponibilização pública dos materiais na prática docente, na atuação de pesquisadores e na preparação de examinandos e alunos de PLA.
\end{abstract}

Palavras-chave: Acervo Celpe-Bras. Exame Celpe-Bras. Português como Língua Adicional

\section{INTRODUÇÃO}

O Certificado de Proficiência em Língua Portuguesa para Estrangeiros, Celpe-Bras, é o exame brasileiro de proficiência em língua portuguesa. O CelpeBras começou a ser desenvolvido em 1993 por uma comissão de professores de universidades brasileiras constituída pelo Ministério da Educação e teve sua primeira aplicação em 1998 (SCHLATTER et al., 2009). A proposta do Celpe-Bras é ser um instrumento de avaliação formulado a partir da visão da linguagem como uma ação conjunta e social, e o conceito de proficiência que fundamenta o exame consiste no "uso adequado da língua para desempenhar ações no mundo" (BRASIL, 2006, p. 3). Nessa perspectiva, a avaliação é definida com "base nas necessidades de uso da língua-alvo" e no "que esse candidato consegue fazer na língua-alvo" (BRASIL, 2006, p. 3), e traz características compatíveis com a noção bakhtiniana de gêneros do discurso (SCHLATTER et al., 2009, p. 12), segundo a

\footnotetext{
1 Doutoranda em Letras pela Universidade Federal do Rio Grande do Sul e professora do Curso de Letras da Universidade do Vale do Rio dos Sinos

${ }^{2}$ Graduanda em Letras pela Universidade Federal do Rio Grande do Sul

3 Doutora em Linguística Aplicada e professora do Programa de Pós-Graduação em Letras da Universidade Federal do Rio Grande do Sul
} 
qual "cada esfera de utilização da língua elabora seus tipos relativamente estáveis de enunciados" (BAKHTIN, 2003, p. 262). Por meio de uma única prova, o CelpeBras certifica quatro níveis de proficiência: Intermediário, Intermediário Superior, Avançado e Avançado Superior. Abaixo do nível Intermediário não há certificação.

Uma das razões para que o Celpe-Bras apresente tais características foi a tentativa de atuar como redirecionador de ensino do Português como Língua Adicional (PLA), que era, à época do desenvolvimento do exame, ainda muito pautado em análises contrastivas e repetição de estruturas (SCHLATTER et al., 2009). Essa tentativa de atuar como direcionador do ensino é chamada pela literatura da área de "washback by design" (SCARAMUCCI, 2004, p. 215). Estudos posteriores sobre o Celpe-Bras e suas contribuições para o ensino de PLA evidenciam essa influência (COSTA, 2005; OHLWEILER, 2006; COSTA, 2013, COSTA E CARVALHO, 2013, entre outros). Para Costa e Carvalho (2013), o CelpeBras estimula o trabalho em sala de aula com textos de circulação pública, promovendo o redirecionamento das práticas pedagógicas a fim de que os examinandos utilizem a língua portuguesa para desempenhar funções sociais. Segundo Ohlweiler (2006, p. 9), o exame também possibilita uma preparação mais adequada de estudantes para obterem o certificado e poderem atuar de forma mais proficiente em contextos relevantes para suas áreas de interesse, profissionais e acadêmicas (OHLWEILER, 2006, p. 9).

Apesar da importância adquirida pelo exame nos contextos de avaliação e ensino de PLA em seus primeiros 15 anos de existência, até 2013 não existia um banco de dados online que reunisse os documentos públicos relacionados ao exame, como os manuais, editais e portarias, tampouco as provas já aplicadas, que eram de acesso apenas aos postos aplicadores do exame e aos professores e alunos que tivessem relações com essas instituições. A fim de democratizar 0 acesso a esses materiais, em 2014, foi lançado o portal Acervo Celpe-Bras, que reúne e disponibiliza publicamente as provas já aplicadas no exame e os documentos públicos relativos a ele, além de reunir as pesquisas já publicadas sobre o Celpe-Bras e apresentar dados e curiosidades relacionados ao exame.

Por ser o único exame brasileiro reconhecido oficialmente como certificação em PLA, o Celpe-Bras tem tido uma crescente procura por pessoas interessadas em certificar sua proficiência, tendo contabilizado mais de onze mil examinandos 
inscritos em 2019. Atualmente, é possível realizar a prova em 125 Postos Aplicadores, distribuídos em 41 países (SIRIANNI et al., 2019). O Manual do Examinando (BRASIL, 2015, p. 8) informa que o certificado é exigido para o ingresso em programas de estudos acadêmicos no Brasil, para a validação de diplomas estrangeiros e para a inscrição profissional em algumas entidades de classe. Além disso, desde 2018 o exame também vem sendo usado no processo de naturalização ${ }^{4}$. $\mathrm{O}$ gráfico abaixo apresenta o número anual de examinandos inscritos homologados no Celpe-Bras ${ }^{5}$ :

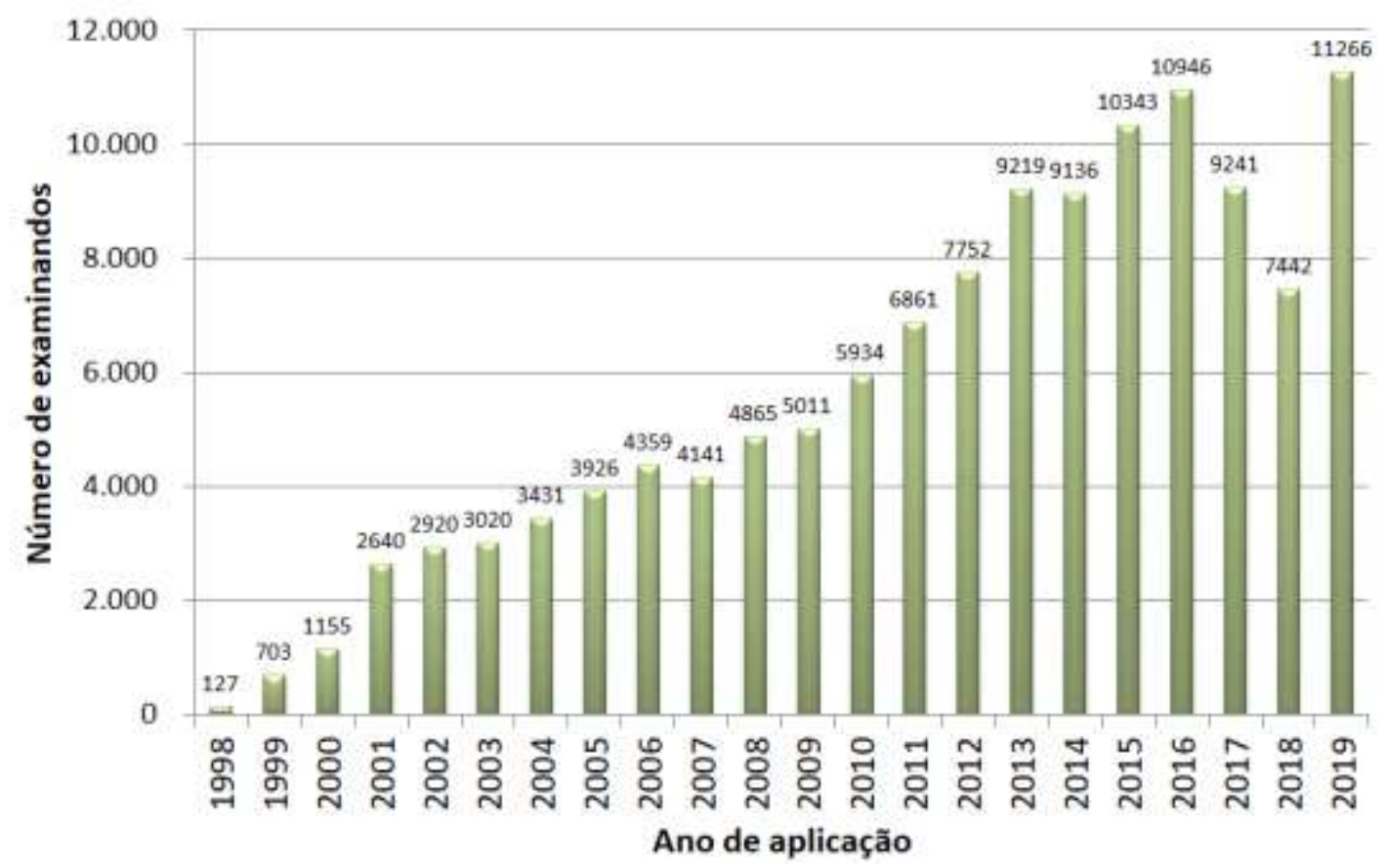

Gráfico 1: Número anual de examinandos do exame Celpe-Bras

Fonte: Adaptado de SCHLATTER et al. (2009) e DAMAZO (2012) por Ellen Yurika Nagasawa.

Dados de MEC e INEP. Disponível em: <http://www.ufrgs.br/acervocelpebras/>

O gráfico a seguir apresenta o percentual de examinandos que recebeu a certificação em cada um dos níveis na edição de 2018:

\footnotetext{
${ }^{4} \mathrm{O}$ procedimento de naturalização ordinária de estrangeiros no Brasil passou a exigir a certificação por meio do Celpe-Bras a partir da publicação da Portaria Interministerial no 11, de 3 de maio de 2018, do Ministério da Justiça. Essa portaria foi posteriormente alterada pela Portaria Interministerial $\mathrm{n}^{\circ} 16$, de 3 de outubro de 2018, que alterou a exigência, passando a listar o exame Celpe-Bras como uma das possibilidades de comprovação de proficiência em língua portuguesa para 0 processo de naturalização.

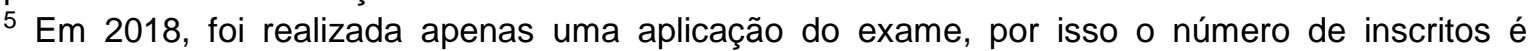
significativamente menor do que nos demais anos, em que foram realizadas duas aplicações.
}

Revista de Letras JUÇARA, Caxias - Maranhão, v. 03, n. 02, p. 241 - 257, dez. 2019 | 241 


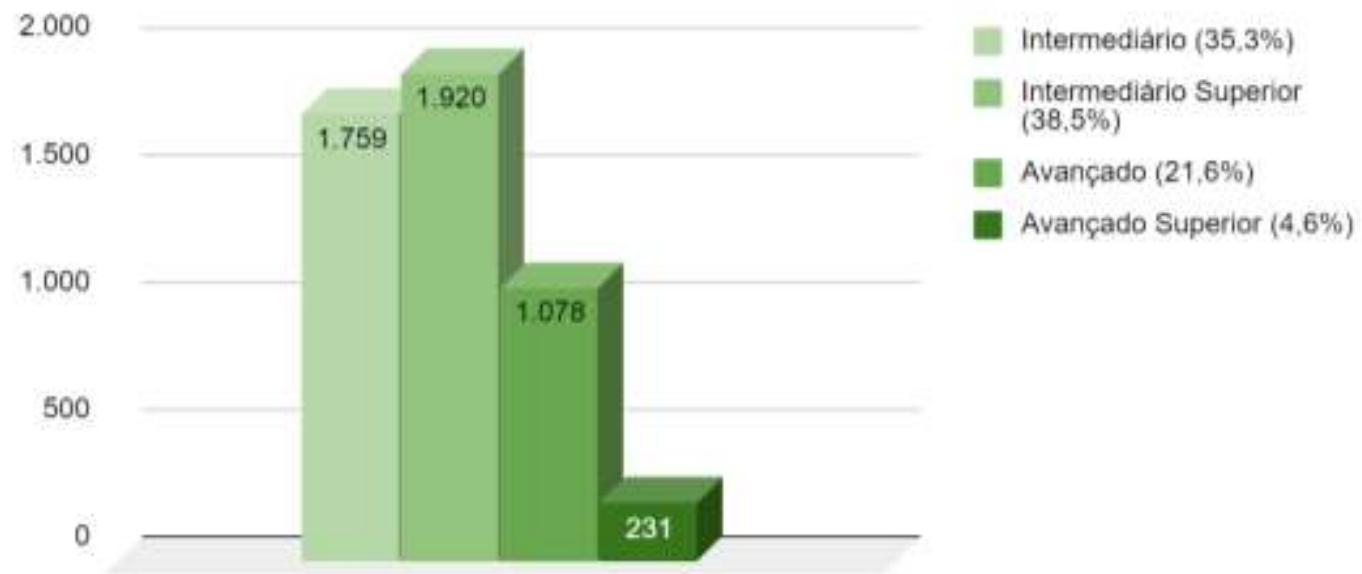

Gráfico 2: Resultado de 2018 do número de examinandos por nível de certificação Fonte: AUTOR, 2018. Disponível em: <http://www.ufrgs.br/acervocelpebras/>

Como podemos verificar no gráfico 2, o nível Intermediário Superior apresenta o maior número de examinandos certificados, seguido pelo nível Intermediário. De acordo com Divino (2017), o nível Intermediário é o nível que mais certificou examinandos na história do exame ${ }^{6}$.

Em relação aos usos de um exame na sociedade, McNamara (2000, p. 4) indica que testes de línguas desempenham um papel poderoso na vida das pessoas, pois atuam como portais de passagens em importantes momentos de transição educacional, profissional e de mudança de um país para outro. Segundo o autor, testes são utilizados para abrir ou fechar portas sociais, sejam elas de instituições educacionais, empresas ou até mesmo de países. Shohamy considera os testes de proficiência linguística como "um dos instrumentos mais poderosos nas sociedades modernas" (SHOHAMY 2011, p. 426), pois são usados como instrumentos de manutenção de línguas dominantes e perpetuação de ideologias. Já Scaramucci (2004) aponta que o conhecimento sobre os exames é refletido na prática docente e ressalta a importância da explicitação do construto teórico do

6 Os programas do governo brasileiro, PEC-G e PEC-PG (http://www.dce.mre.gov.br/PEC/PG/candidatura.php), e o edital de seleção para ingresso em curso de graduação de pessoas em situação de refúgio da UFRGS (http://www.ufrgs.br/prograd/processos-seletivos/ingresso-de-refugiados) exigem a apresentação do Celpe-Bras para a participação dos candidatos, apesar de não indicar o nível exigido. Do mesmo modo, a portaria que dispõe sobre os procedimentos para solicitação de naturalização apenas solicita a apresentação do certificado (Portaria Interministerial N 11, de 3 de maio de 2018 e Portaria Interministerial $\mathrm{N}^{\circ} 16$, de 3 de outubro de 2018). No entanto, o Conselho Federal de Medicina indica a exigência do certificado em nível intermediário (Resolução № 2.216, de 27 de setembro de 2018) para revalidação de diplomas.

Revista de Letras JUÇARA, Caxias - Maranhão, v. 03, n. 02, p. 241 - 257, dez. 2019 | 242 
Celpe-Bras para potencializar os efeitos retroativos desejados no ensino de PLA. Sendo assim, entendemos que o acesso aos manuais, provas, especificações, matrizes e estudos realizados sobre o exame têm forte possibilidade de influenciar o ensino de PLA e, portanto, reforça a importância da disponibilização do Acervo Celpe-Bras.

Considerado um exame de alta relevância (SCHLATTER et al., 2009), diversas pesquisas já demonstraram o papel do Celpe-Bras como um instrumento de política linguística (MACHADO, 2010; SOBROSA; STURZA, 2011; DINIZ, 2012; DIAS; PINTO, 2017; MARTINS, 2018), entendida não somente como os objetivos e propósitos políticos, mas como a materialização de fato dessas intenções (DORIGON, 2016). Pesquisas da área da Linguística Aplicada apontam que o Celpe-Bras gera impacto em áreas como: formação de professores (OHLWEILER, 2006; RODRIGUES, 2006; COSTA, 2013); elaboração de material didático (QIAORONG, 2008; LI, 2009; ZHANG, 2017); desenvolvimento de cursos (VARELA, 2002; NAGASAWA, 2018); desenvolvimento de instrumentos de avaliação (COSTA, 2005; SANTOS, 2007) e parâmetros curriculares (KRAEMER, 2012; MITTELSTADT, 2013; SCHOFFEN; MARTINS, 2016).

Dos trabalhos mencionados acima, que se referem aos impactos do CelpeBras na sociedade, podemos verificar que a maior parte foi publicada no período anterior à democratização do acesso aos materiais do exame, proporcionada pela construção e disponibilização pública do Acervo Celpe-Bras. Decorre disso o fato de grande parte das pesquisas realizadas sobre o Celpe-Bras terem sido feitas por pesquisadores de instituições que já eram credenciadas como Postos Aplicadores do exame ${ }^{7} \mathrm{e}$, portanto, tinham acesso aos documentos e às provas, o que de certa maneira limitava o efeito do exame a estas pessoas e lugares. Depois da divulgação do Acervo Celpe-Bras, os materiais relacionados ao exame podem ser acessados por qualquer pessoa em qualquer lugar do mundo com acesso à internet, como mostram os dados de acesso e relatos que serão apresentados neste artigo. Segundo Rodrigues (2006), é importante que as provas, pesquisas e manuais do e sobre o exame sejam públicos para que os professores possam se aproximar da concepção de linguagem do exame e, desse modo, redirecionar o

${ }^{7}$ UFRGS, Unicamp, UFMG, UnB, IBEQ, ICBV, por exemplo.

Revista de Letras JUÇARA, Caxias - Maranhão, v. 03, n. 02, p. 241 - 257, dez. 2019 | 243 
ensino de PLA. Em uma análise feita por Truyllio e Schoffen (2018) sobre o acervo de pesquisas relacionadas ao Celpe-Bras, os dados indicaram que, após a disponibilização pública do Acervo Celpe-Bras, o número de pesquisas referentes ao exame apresentou um significativo aumento, sendo a temática mais pesquisada entre 2014 e 2017 a análise das provas e do processo de avaliação, que compreendem $31,3 \%$ das pesquisas realizadas nesse período, o que demonstra a importância da democratização do acesso às provas já aplicadas também para a realização de pesquisas sobre o exame.

Sabe-se que o acesso aos materiais de exames de alta relevância pode influenciar o tipo e a intensidade de seus efeitos retroativos (SPRATT, 2005); nesse sentido, Sirianni et al. (2019) apontaram desdobramentos do Acervo Celpe-Bras no campo de pesquisa sobre o Celpe-Bras, mostrando o crescente número de trabalhos acadêmicos que utilizam os dados disponibilizados no Acervo. Além disso, Schoffen et al. (2017) apresentam dados da ferramenta Google Analytics, ferramenta de monitoramento do tráfego de visitação e estatísticas do site do Acervo, que revelou o acesso de usuários a partir de mais de 140 países, com picos de acessos ao redor das datas de aplicação das provas, predominantemente oriundos de países da América do Sul, mostrando o Brasil como o país líder de acessos. As autoras sugerem, pelas informações registradas no Google Analytics, que o Acervo é utilizado por um grupo de usuários assíduos no Brasil, formado possivelmente por professores e pesquisadores, que acessam a página frequentemente. Nos dias próximos à aplicação do exame, se juntam a esses usuários um grupo maior, que, por seu comportamento de acesso, possivelmente inclui os candidatos ao exame (Schoffen et al., 2017). O estudo mostra que a aba na qual se encontram as provas já aplicadas é a que registra o maior número de visitas.

Para confirmar o que já se sabia sobre os acessos ao Acervo (Schoffen et al., 2017), foi desenvolvido um questionário com o objetivo de obter mais informações sobre os usuários do portal e os usos que estavam sendo feitos dele. Visto que o número de candidatos que realizam o exame vinha aumentando nos últimos anos, um importante propósito deste questionário era verificar se, dentre os usuários professores, haveria percepções de mudança em suas metodologias e qual teria sido o impacto dessas mudanças no ensino preparatório ao exame Celpe- 
Bras após a disponibilização pública do Acervo. Este propósito foi pensado a partir da demanda no ensino de português com objetivos de certificação de proficiência, que é cada vez maior, e exige uma formação de professores com especialização em preparação de examinandos. Dentre os usuários pesquisadores, o questionário também tinha a finalidade de identificar se haveria percepções de que o acesso ao Acervo alterou seus trabalhos de pesquisa. O questionário teve seu link publicado no Acervo Celpe-Bras entre os meses de junho e outubro de 2018 e recebeu mais de 900 respostas. Os dados gerados a partir das respostas obtidas neste questionário serão apresentados e analisados ao longo deste artigo.

\section{METODOLOGIA}

O objetivo desta pesquisa ${ }^{8}$ foi mapear o perfil dos usuários do Acervo CelpeBras e identificar os usos feitos do portal pela comunidade a partir do relato dos usuários. A partir desse mapeamento, buscamos compreender a importância da disponibilização pública de materiais do Celpe-Bras para o ensino e a formação de professores de PLA e para a preparação de candidatos ao exame.

\subsection{DESENHO}

Para alcançar os objetivos do estudo, baseada em metodologia analítica mista (CHRISTENSEN et al., 2015) e tendo objetivo descritivo e não experimental ou inferencial, a geração de dados ocorreu por meio de um questionário disponibilizado no Acervo $^{9}$ com convite para participação voluntária aos usuários que acessaram o portal entre os dias 16 de junho e 4 de outubro de 2018.

Nesta pesquisa, foi realizado um estudo transversal, que é o método no qual a geração de dados é realizada durante um tempo breve, suficiente para que os participantes da amostra do público alvo participem apenas uma vez. De acordo com Christensen et al. (2015), o questionário é um instrumento de geração de dados de auto relato (self-report data collection instrument), preenchido pelo próprio

\footnotetext{
${ }^{8}$ A pesquisa foi aprovada pelo Comitê em Ética em Pesquisa da Universidade Federal do Rio Grande do Sul em 10 de fevereiro de 2018, sob o processo no 2.481.889.

${ }^{9}$ Registramos aqui nossos agradecimentos à Prof. Dra. Ana Beatriz Arêas da Luz Fontes pela contribuição no desenvolvimento do desenho e instrumento de pesquisa utilizados.
}

Revista de Letras JUÇARA, Caxias - Maranhão, v. 03, n. 02, p. 241 - 257, dez. 2019 | 245 
participante de pesquisa. Segundo os autores, o questionário deve ser utilizado quando se precisam medir atitudes, atividades, opiniões ou crenças de indivíduos, podendo ser possível realizar análises das relações entre as variáveis, estimativas e identificações de como os subgrupos se diferem (CHRISTENSEN et al., 2015, p. 336).

\subsection{INSTRUMENTO}

O questionário, elaborado no programa Qualtrics, se caracteriza como um instrumento misto, com perguntas fechadas do tipo categórica binária (possibilidade de assinalar apenas uma entre duas respostas), categórica de múltipla escolha (possibilidade de escolher mais de uma resposta), de contingência (a resposta escolhida direciona o questionário para perguntas diferentes) e de escala Likert (escala psicométrica com cinco categorias intervalares). 0 questionário apresentou também uma questão de resposta aberta para os respondentes que assinalaram o perfil de professor e pesquisador e teve como objetivo obter uma narrativa de suas percepções em relação a mudanças em seu trabalho após o acesso ao Acervo. Ao final do questionário, todos os participantes também puderam deixar opiniões, críticas ou sugestões em relação ao site em um espaço aberto para respostas livres.

\subsection{PARTICIPANTES}

Como descrito anteriormente, o público-alvo da pesquisa é composto por usuários do Acervo Celpe-Bras e a participação no estudo foi restrita aos usuários que acessaram o portal durante o tempo em que o link esteve ativo para 0 recebimento de respostas.

Participaram da geração de dados um total de 911 respondentes, de acordo com o registro do Qualtrics. Foram registrados 911 questionários iniciados e, desse total, 678 (74,42\%) participantes acessaram e encerraram o questionário dentro da janela de tempo prevista, de até 10 minutos. O programa registrou acessos diários que variaram entre 1 e 31 participantes iniciando o questionário e, dos 911 que iniciaram, 90,56\% (825) concordaram com o TCLE e 62,90\% (573) foram além da 
primeira pergunta. O programa registrou que $484(53,13 \%)$ pessoas completaram a última pergunta de múltipla escolha e $302(33,15 \%)$ foram até a pergunta que encerrava o questionário e solicitava uma resposta descritiva. $\mathrm{O}$ restante dos participantes fechou o link ou encerrou o questionário no decorrer do processo.

\subsection{ANÁLISE DE DADOS}

O questionário foi elaborado com dois tipos de questões: fechadas (dentre as quais o respondente poderia, além de escolher uma resposta previamente preparada, selecionar a opção "outra" e escrever uma resposta própria), e abertas (dissertativas). Desse modo, o instrumento gerou dados numéricos, a partir das respostas fechadas, e textuais, respostas das questões abertas. As respostas dissertativas foram, então, classificadas em categorias e tratadas quantitativamente junto aos dados das respostas fechadas. A análise geral dos dados, no entanto, foi qualitativa, uma vez que levou em consideração a interpretação dos dados obtidos e a busca por uma visão êmica dentro de uma perspectiva de pesquisa interpretativa (MASON, 1996). Entre os três grupos aos quais as perguntas estavam direcionadas, havia perguntas em comum e perguntas restritas para cada um dos grupos individualmente; por esse motivo, e também pela desistência de participantes ao longo do questionário, o total de respostas não foi equivalente para todas as questões, como poderá ser visto na próxima seção. Os dados percentuais apresentados neste artigo foram elaborados contabilizando o número obtido de respostas por questão.

\section{RESULTADOS E DISCUSSÕES}

O questionário tinha como objetivo identificar usuários do Acervo Celpe-Bras e os usos que estavam sendo feitos dele. A primeira hipótese formulada para estes usuários foi a de que o grupo de maior número seria o de professores que buscavam encontrar materiais para utilizar em suas aulas de preparação para o exame Celpe-Bras. Os dados apresentados a seguir, como veremos, sugerem um perfil diferente do esperado. 


\subsection{PERFIL DE USUÁRIOS DO ACERVO CELPE-BRAS}

Contabilizando os 825 participantes que concordaram com os termos do TCLE, $18(2,18 \%)$ tinham menos de 18 anos e não puderam seguir o questionário, $70(8,48 \%)$ tinham entre 18 - 20 anos, $311(37,70 \%)$ tinham entre 21 - 30 anos, 218 $(26,42 \%)$ tinham entre 31 - 40 anos, $121(14,67 \%)$ tinham entre 41 - 50 anos, 65 $(7,88 \%)$ tinham entre 51 - 60 anos e $22(2,67 \%)$ tinham acima de 60 anos. Destes 825, apenas 573 confirmaram a pergunta referente ao gênero e são, em sua maioria, mulheres, totalizando $58,29 \%$ dos participantes que responderam a esta pergunta. Em relação à nacionalidade, $165(28,8 \%)$ dos 573 respondentes são brasileiros, enquanto 408 (71,20\%) são estrangeiros. Destes 408 , os grupos mais numerosos são de colombianos (23,7\%), seguidos por peruanos (18,3\%), cubanos $(15,5 \%)$ e argentinos (13,2\%). No tocante à residência, dos 573 respondentes, 264 $(46,1 \%)$ residem no Brasil, enquanto 309 (53,9\%) residem em outros países. Dentre esses, $54(17,47 \%)$ residem na Colômbia, 33 (10,68\%) residem no Peru e outros $33(10,68 \%)$ residem na Argentina. Abaixo, apresentamos um mapa mundi em que estão sinalizados os países onde residem os respondentes do questionário.

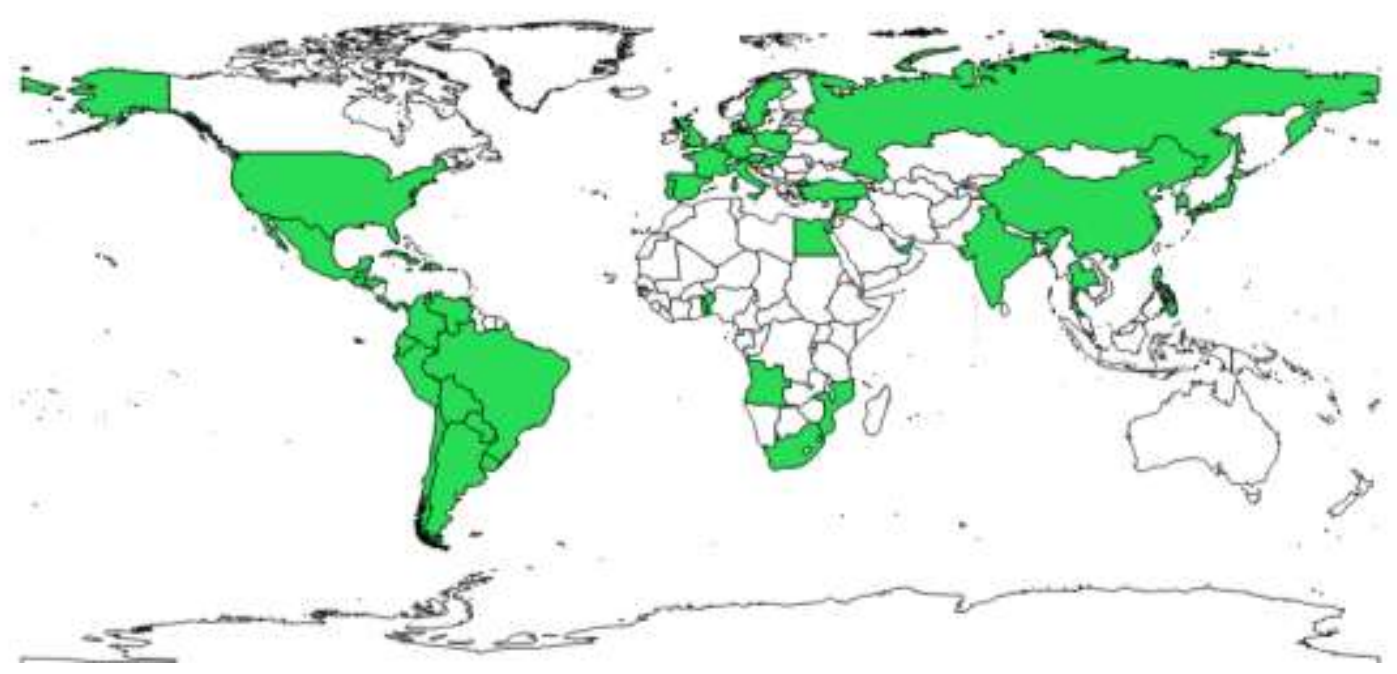

Figura 1: Mapa mundi referente aos países em que residem os respondentes do questionário Fonte: AUTOR, 2019

Mais da metade dos participantes $(52,32 \%)$ tem o espanhol como sua língua materna. O português também apareceu como língua materna para um alto índice de participantes $(31,29 \%)$, o que sugere que estes seriam professores e pesquisadores. Em terceiro lugar, está o inglês, representando apenas $3,7 \%$ dos 
participantes. Como línguas adicionais, $61,78 \%$ dos respondentes declaram falar também inglês, $42,60 \%$ declaram falar português e $23,73 \%$ dizem falar espanhol. Na questão em que o participante deveria escolher a opção que melhor descreveria seu perfil de usuário, 370 (56,32\%) afirmaram ser estudantes, 181 (27,54\%) afirmaram ser professores e 106 (16,14\%) afirmaram ser pesquisadores. Em relação à escolarização, $54 \%$ dos respondentes afirmaram ter concluído um curso de graduação.

Com base nos dados acima, é possível traçar o perfil dos usuários que mais acessam o Acervo Celpe-Bras. Esses usuários são, em sua maioria, estudantes do sexo feminino entre 21 e 40 anos de idade, que concluíram a graduação, residem em países da América do Sul e utilizam o Acervo Celpe-Bras para estudar. As informações obtidas por meio das respostas indicam que a maioria dos usuários que acessaram o Acervo durante o período pesquisado são estudantes interessados em estudar ou trabalhar no Brasil e procuram o site para consultar as provas e estudar para o exame, confirmando a hipótese levantada por Schoffen et al. (2017) de que nas datas próximas à aplicação das provas os picos de acesso ao site acontecem por usuários candidatos ao exame Celpe-Bras.

\subsection{USO DO ACERVO CELPE-BRAS}

Nesta seção serão apresentados os perfis de cada grupo de usuários do Acervo Celpe-Bras, bem como o uso que cada grupo faz da plataforma.

\subsubsection{Estudantes}

Os estudantes, como apresentado na seção anterior, representam a maior parte dos usuários do Acervo Celpe-Bras, com 370 respondentes. A maioria destes estudantes estuda português há menos de 5 anos e considera seu nível de conhecimento no português como intermediário, como mostra o gráfico abaixo: 


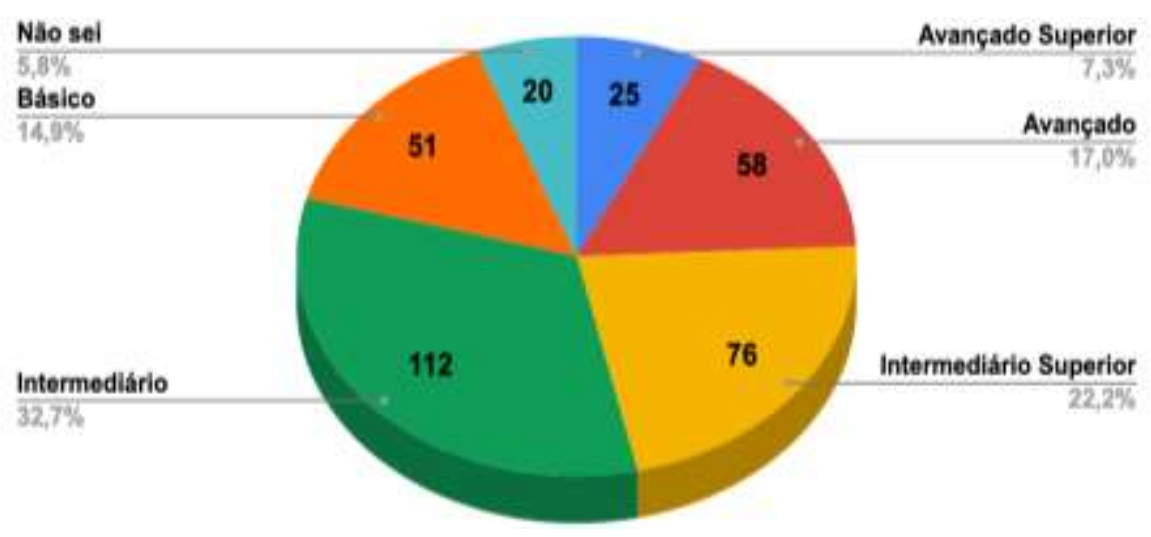

Gráfico 3: Nível de conhecimento do português declarado pelos participantes Fonte: AUTOR, 2019

O nível Intermediário é o nível mais baixo de proficiência certificado pelo Celpe-Bras. A partir disso, pode-se inferir o porquê de, entre os estudantes, o grupo que mais tenha acessado o site para consultar provas no período em que o questionário esteve disponível seja os que declaram que sua proficiência se encaixa nas faixas dos níveis Intermediários (54,9\%). Além de ser o nível mais baixo de certificação do exame, este foi o nível em que houve o maior número de examinandos certificados na maioria das edições do Celpe-Bras (vide Gráf. 2).

Dos 696 participantes que responderam à questão referente à maneira como utilizava o Acervo, $384(55,17 \%)$ afirmaram utilizar o site para estudar. A maior parte dos estudantes afirmou acessar os materiais sozinho para estudo autônomo e não em aula com professor.

Verifica-se, portanto, que o Acervo Celpe-Bras funciona, para alguns usuários, como uma ferramenta que permite o acesso a informações valiosas que abrem caminho à possibilidade de certificação do exame Celpe-Bras, e, consequentemente, a oportunidades de participação em práticas sociais brasileiras legitimadas por esse documento.

\subsubsection{Professores}

Os professores formam o segundo grupo com maior número de respondentes contabilizando 181. Destes professores de PLA, 33,33\% ensina em cursos de línguas, 30,22\% ensina português em universidades e 27,55\% trabalha de modo autônomo. Dos 125 professores de PLA que responderam à questão 
referente ao tempo que trabalham na área, $60 \%$ trabalha há mais de 1, porém menos de 10 anos. Destes 125 profissionais, 97 (77,60\%) trabalha como professor para preparação de examinandos ao exame Celpe-Bras. Os respondentes relataram que o material disponível no Acervo é majoritariamente utilizado para realizar simulados em aula $(30,64 \%)$, desenvolver material didático $(26,89 \%)$, entregar como tarefa de casa para os alunos $(20,43 \%)$ e realizar reflexões teóricas sobre o exame $(20,43 \%)$.

No que diz respeito à metodologia de ensino para preparação de examinandos antes da disponibilização do Acervo e às mudanças metodológicas percebidas depois do acesso aos materiais disponibilizados, apenas $5,62 \%$ dos 160 professores que responderam à questão alegam não ter percebido mudanças em sua prática docente após o acesso ao Acervo. Os gráficos a seguir mostram as metodologias que os professores relatam mais utilizar em sala de aula antes e depois da disponibilização do Acervo, sendo possível fazer uma comparação e perceber quais mudanças estes professores consideram terem ocorrido em sua metodologia ${ }^{10}$ :

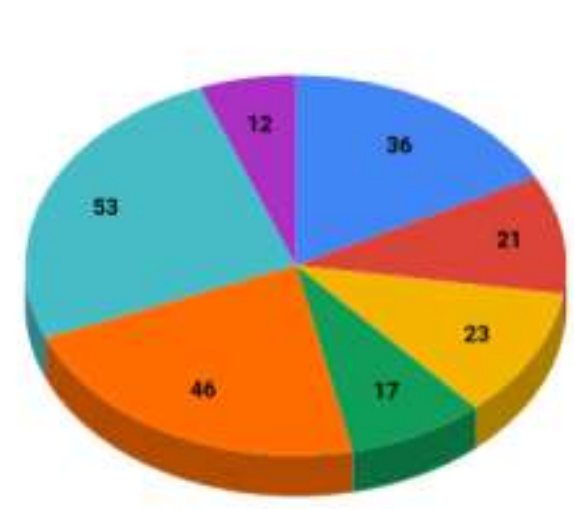

antes

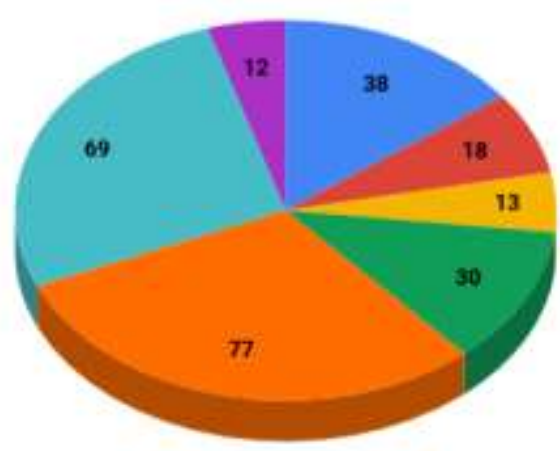

depois

Gráfico 4: Atividades mais realizadas nas aulas de preparação para o Celpe-Bras antes e depois da disponibilização do Acervo Celpe-Bras

Fonte: AUTOR, 2019

Comparando os gráficos acima, pode-se perceber o impacto da disponibilização das provas no Acervo nas atividades realizadas em sala de aula. O gráfico à direita ilustra o crescimento da utilização do material disponibilizado no Acervo, uma vez que o número de professores realizando simulados e baseando

${ }^{10}$ É importante aqui ressaltar que, nas questões representadas nos gráficos, cada participante poderia escolher mais de uma opção. 
seu ensino em tarefas cresceu, enquanto o foco na gramática e o uso de livros didáticos diminuiu. Podemos inferir, então, que a disponibilização das provas já aplicadas permite aos professores se desprender mais do livro didático, já que os dados sugerem que os professores estejam utilizando as edições antigas das provas do Celpe-Bras para planejar suas aulas e utilizando-as como material didático no lugar dos livros.

Os professores que dispunham do acesso às provas do Celpe-Bras antes da disponibilização do Acervo tinham, na maioria das vezes, vínculo com algum Posto Aplicador do exame, o que restringia apenas aos alunos destes a possibilidade de conhecer bem o exame e ter acesso a uma preparação mais qualificada para obter um melhor desempenho. Tendo em vista que, após a disponibilização do Acervo, qualquer professor em qualquer lugar do mundo com acesso à internet pode utilizar os materiais do Acervo para preparar suas aulas, é possível dizer que o Acervo Celpe-Bras influenciou positivamente o ensino preparatório para o exame, uma vez que possibilitou aos professores utilizar materiais autênticos, levar os alunos a conhecer melhor a prova e utilizar nas aulas de preparação uma abordagem muito mais aproximada da realidade do exame.

Observa-se que o Acervo, no relato dos professores que responderam ao questionário, vem assumindo um papel de direcionamento do ensino de português, não só por possibilitar o acesso a materiais que auxiliam na preparação de aulas, mas também se configurando como um repositório que possibilita a formação docente. Dessa forma, o exame Celpe-Bras concretiza-se como instrumento de política linguística capaz de exercer efeito positivo e redirecionador de ensino de PLA através do acesso a seus materiais possibilitado pelo Acervo Celpe-Bras.

\subsubsection{Pesquisadores}

Os pesquisadores compõem a menor parcela de respondentes do questionário. Dos 87 usuários que se identificaram como pesquisadores, 54 $(62,07 \%)$ informaram que iniciaram suas pesquisas sobre o Celpe-Bras depois da divulgação do Acervo. O gráfico abaixo ilustra os diferentes temas de pesquisa deste grupo de pesquisadores: 


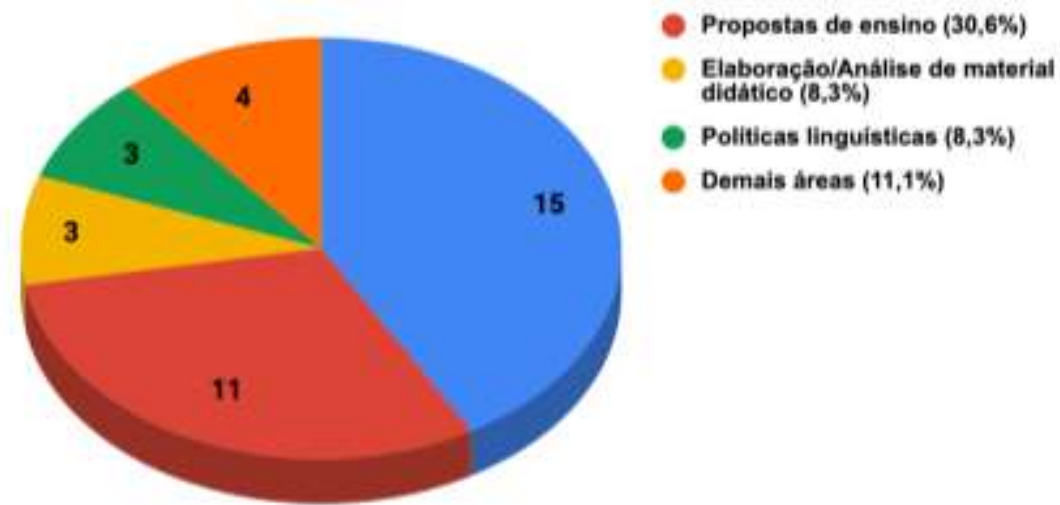

Gráfico 5: Temas pesquisados pelos respondentes do questionário Fonte: AUTOR, 2019

De acordo com o gráfico acima, a maioria dos respondentes têm suas pesquisas direcionadas para o ensino, compondo $80,6 \%$ das respostas, se agrupadas as categorias Avaliação, Propostas de ensino e Elaboração/Análise de material didático. Além das provas e manuais, um fator que pode ter influenciado os pesquisadores no direcionamento de seus temas e metodologias de pesquisa é a aba Pesquisas do Acervo, que relaciona as pesquisas e trabalhos realizados acerca do exame, reunindo e facilitando o acesso a estudos já realizados sobre o Celpe-Bras.

\section{CONSIDERAÇÕES FINAIS}

A partir dos resultados obtidos com o questionário disponibilizado na página do Acervo Celpe-Bras, foi possível traçar o perfil dos usuários do Acervo e descrever os usos que esses usuários fazem dos materiais ali disponibilizados. Os dados apresentados revelam o uso do Acervo Celpe-Bras especialmente para estudo e busca pela certificação por parte de estudantes candidatos ao exame. Além disso, o estudo demonstrou que o Acervo vem exercendo influência na prática docente de professores e, portanto, auxiliando na formação continuada de professores da área de PLA, principalmente de professores de cursos preparatórios ao exame.

No campo de pesquisa sobre o exame, verificou-se o impacto da disponibilização pública dos materiais na atuação de pesquisadores, expandindo e fortalecendo essa área de estudos e possibilitando a crescente produção de 
conhecimentos e o aprimoramento desse instrumento de avaliação. As análises ainda confirmam a importância do Celpe-Bras enquanto instrumento de política linguística brasileiro e demonstram como o Acervo se constitui como um mediador entre os usuários do exame e a materialização dessas políticas linguísticas. Para os estudantes, maioria dos usuários do Acervo, a disponibilização das provas já aplicadas é importante para que possam conhecer o formato e as exigências de avaliação do exame e possam, assim, melhor se preparar para obter um bom resultado.

Um dos importantes efeitos retroativos da democratização dos materiais no Acervo foi que, posteriormente à disponibilização pública do Acervo Celpe-Bras no domínio da UFRGS, as provas já aplicadas passaram a ser disponibilizadas também no site oficial do Inep e, atualmente, há também alguns áudios e vídeos do exame disponíveis no canal do Inep no Youtube; a disponibilização dos materiais em mais locais possibilita que mais pessoas que buscam informações consigam ter acesso às mesmas.

Após a análise das respostas ao questionário, foi possível conhecer o perfil dos usuários do Acervo e com que finalidade este é utilizado. Apesar de a hipótese inicial haver sido de que o Acervo era utilizado majoritariamente por professores, os resultados foram ainda mais satisfatórios, uma vez que mostraram que o Acervo é utilizado, sobretudo, pelos próprios candidatos e que também vem ampliando as possibilidades de estudo para pesquisadores. Desse modo, os resultados obtidos condizem com o propósito inicial da idealização do Acervo Celpe-Bras, visto que contribuiu para democratizar o acesso aos dados do exame para estudantes, professores e pesquisadores, fomentando e promovendo o ensino e a pesquisa sobre avaliação em PLA.

\section{USERS ACCOUNTS ON THE ACERVO CELPE-BRAS CONTRIBUTIONS TO THE PORTUGUESE LANGUAGE PROMOTION}

Abstract: The Certificate of Proficiency in Portuguese language for Foreigners, Celpe-Bras, is the brazilian Portuguese proficiency test developed by the Brazilian Ministry of Education, applied since 1998. In 2014, the Acervo Celpe-Bras, an online platform that contains all the documents, tests, manuals and other data regarding the exam, was publicly released by the Avalia research group, from the Universidade Federal do Rio Grande do Sul. The Acervo's availability was extremely relevant for the democratization of access to the data regarding the exam. In order to investigate the impact of the public provision of those materials to PAL (Portuguese as an Additional Language) teaching and learning and to the preparation of candidates, as well as to map users profile, a 
questionnaire was posted online to invite volunteer participation during the period of 2018 exam's registration and application. This article presents quantitative and qualitative data, which indicate the impact of the public release of the materials on teaching practices, to researcher's works and on examinee and PAL students' preparation.

Keywords: Acervo Celpe-Bras. Celpe-Bras Exam. Portuguese as an Additional Language

\section{REFERÊNCIAS}

BAKHTIN, M. Estética da criação verbal. São Paulo: Martins Fontes, 2003.

BRASIL. Manual do candidato do Exame Celpe-Bras. Brasília: Secretaria de Educação Superior (SESu), MEC, 2006.

BRASIL. Manual do Examinando. Brasília: Secretaria de Educação Superior (SESU), MEC, 2015.

CHRISTENSEN, L. B.; JOHNSON, R. B.; TURNER, L. A. Research Methods, Design, and Analysis. 12th edition. Harlow: Pearson Education Limited, 2015.

COSTA, E. V. A reconstrução de um teste estrutural em um teste de desempenho: uma proposta de reflexão. Trabalho de Conclusão de Curso (Licenciatura em Letras) - Universidade Federal do Rio Grande do Sul. Porto Alegre, 2005.

. Práticas de formação de professores de português língua adicional em um instituto cultural brasileiro no exterior. Dissertação (Mestrado em Linguística Aplicada) - Universidade Federal do Rio Grande do Sul. Porto Alegre, 2013.

COSTA, E. V.; CARVALHO, S. Uso da linguagem e letramento: uma proposta de reflexão sobre a avaliação de proficiência no exame CELPE-BRAS. Revista de Letras Norte@mentos, v. 6, p. 251-266, 2013.

DAMAZO, L. O. A modalização na produção de textos em português como língua estrangeira. Dissertação (Mestrado em Estudos da Linguagem) - Centro Federal de Educação Tecnológica de Minas Gerais. Belo Horizonte, 2012.

DIAS, A. L. K.; PINTO, J. P. Ideologias linguísticas e regimes de testes de língua para migrantes no Brasil. Revista Brasileira de Linguística Aplicada [online]. vol. 17, n. 1, p. 61-81, 2017.

DINIZ, L. R. A. Política linguística do Estado brasileiro para a divulgação do português em países de língua oficial espanhola. Trabalhos em Linguística Aplicada, Campinas, n 51.2, p. 435-458, jul./dez. 2012.

DIVINO, L. S. Panorama dos níveis de certificação obtidos pelos examinandos no Celpe-Bras: implicações para a pesquisa e a avaliação. In: IV Simpósio Internacional Celpe-Bras, 2017, Curitiba. Caderno de Resumos, Curitiba, 2017, p. 72. Disponível em:<http://www.celin.ufpr.br/portal/sincelpe/wp-content/uploads/site s4/2017/04/Caderno-de-ResumosFinal2.pdf> 
DORIGON, T. O Celpe-Bras como Instrumento de Política Linguística: um Mediador entre Propósitos e Materializações. Dissertação (Mestrado em Linguística Aplicada) - Universidade Federal do Rio Grande do Sul. Porto Alegre, 2016.

KRAEMER, F. F. Português Língua Adicional: progressão curricular com base em gêneros do discurso. Dissertação (Mestrado em Letras) - Universidade Federal do Rio Grande do Sul. Porto Alegre, 2012.

LI, Y. A preparação de candidatos chineses para o exame Celpe-Bras: aprendendo o que significa "uso da linguagem". Dissertação (Mestrado em Linguística Aplicada) - Universidade Federal do Rio Grande do Sul. Porto Alegre, 2009.

MACHADO, T. R. M. O Celpe-Bras e outras políticas linguísticas brasileiras pela promoção do português do Brasil. Fólio - Revista de Letras, Vitória da Conquista, v. 2, n. 2, p. 63-81, jul./dez. 2010.

MARTINS, A. F. Rastros de mudanças epistemológicas na área de português como língua adicional: o exame Celpe-Bras como mecanismo de políticas linguísticas. BELT - Brazilian English Language Teaching Journal, Porto Alegre, v. 9, n. 1, p. 223-243, 2018.

MASON, J. Qualitative researching. Londres: Sage, ed. 2, 1996.

MCNAMARA, T. Language Testing. Oxford: Oxford University Press, 2000.

MITTELSTADT, D. D. Orientações curriculares e pedagógicas para o nível avançado de português como língua adicional. Dissertação (Mestrado em Letras) Universidade Federal do Rio Grande do Sul. Porto Alegre, 2013.

NAGASAWA, E. Y. Português como língua adicional para fins preparação ao exame Celpe-Bras. Dissertação (Mestrado em Linguística Aplicada) - Universidade Federal do Rio Grande do Sul. Porto Alegre, 2018.

OHLWEILER, B. M. D. Criação de um jornal na sala de aula de português língua estrangeira. Dissertação (Mestrado em Linguística Aplicada) - Universidade Federal do Rio Grande do Sul. Porto Alegre, 2006.

QIAORONG, Y. De práticas sociais a gêneros do discurso: uma proposta para o ensino de português para falantes de outras línguas. Dissertação (Mestrado em Linguística Aplicada) - Universidade Federal do Rio Grande do Sul. Porto Alegre, RS, 2008.

RODRIGUES, M. S. A. O exame Celpe-Bras: Reflexões teóricas para o professor de português para falantes de outras línguas. Dissertação (Mestrado em Letras) Universidade Estadual de Campinas. Campinas, 2006.

SANTOS, L. G. Avaliação de desempenho para nivelamento de alunos de português como língua estrangeira. Dissertação (Mestrado em Linguística Aplicada) - Universidade Federal do Rio Grande do Sul. Porto Alegre, 2007.

SCARAMUCCI, M. Efeito retroativo da avaliação no ensino/aprendizagem de línguas: O estado da arte. Trabalhos em Linguística Aplicada, Campinas, v. 43, n. 2, p. 203-226, 2004. 
SCHLATTER, M.; SCARAMUCCI, M. V. R.; PRATI, S.; ACUÑA, L. Celpe-Bras e Celu: impactos da construção de parâmetros comuns de avaliação de proficiência em português e em espanhol. In: FONTANA, M. Z. (Org.) O português do Brasil como língua transnacional. Campinas: RG Editora, 2009.

SCHOFFEN, J. R.; MARTINS, A. F. Políticas linguísticas e definição de parâmetros para o ensino de português como língua adicional: perspectivas portuguesa e brasileira. ReVEL, Porto Alegre, v. 14, n. 26, p. 271-306, 2016.

SCHOFFEN, J. R.; NAGASAWA, E. Y.; SIRIANNI, G.; MACHADO, B. P. Resgatando a história do exame Celpe-Bras: desenvolvimento, disponibilização e estudos sobre o Acervo de provas e documentos públicos do exame Celpe-Bras. Cadernos do IL, Porto Alegre, v. 55, p. 87-113, 2017.

SHOHAMY, E. Assessing multilingual Competencies: adopting construct valid assessment policies. In: The Modern Language Journal, v. 95, n. 3, 2011.

SIRIANNI, G. R.; MENDEL, K.; NAGASAWA, E. Y.; SCHOFFEN, J. R. Os desdobramentos do Acervo Celpe-Bras para o ensino, aprendizagem, avaliação e pesquisa em Português como Língua Adicional. BELT - Brazilian English Language Teaching Journal, Porto Alegre, v. 10, n. 1, 2019.

SOBROSA, D. M.; STURZA, E. R. As Políticas Linguísticas e a Língua Portuguesa: um panorama da colonização ao Celpe-Bras. Revista Ideias, Santa Maria, v. 27, p. 01-10, 2011.

SPRATT, M. Washback and the classroom: the implications for teaching and learning of studies of washback from exams. Language Teaching Research, v. 9, n. 1, p. 5-29, 2005.

TRUYLLIO, L. R.; SCHOFFEN, J. R. Exame Celpe-Bras: atualização e análise do acervo de pesquisas. In: SEMINÁRIO NACIONAL DE ENSINO DE LÍNGUAS E DE LITERATURA - SNELL, IV, 2018, Lajeado. Anais do IV Seminário Nacional de Ensino de Línguas e de Literatura - IV SNELL, Lajeado, 2018, p. 50. Disponível em:<https://www.univates.br/editora-

univates/media/publicacoes/270/pdf_270.pdf>

VARELA, S. M. O efeito retroativo do Celpe-Bras em um curso de português para estrangeiros. Dissertação (Mestrado em Linguística Aplicada) - Universidade de Brasília. Brasília, 2002.

ZHANG, F. Avaliação de desempenho e reescrita como oportunidades de aprendizagem da escrita em português por alunos chineses. Tese (Doutorado em Linguística Aplicada) - Universidade Federal do Rio Grande do Sul. Porto Alegre, 2017.

Data da Submissão:07/11/2019

Data da Aprovação: 09/12/2019 